Article

\title{
Quick, Single-Frequency Dielectric Characterization of Blood Samples of Pediatric Cancer Patients by a Cylindrical Capacitor: Pilot Study
}

\author{
Anooshe Ghanbarzadeh-Daghian ${ }^{\mathbb{D}}$, Mohammad Taghi Ahmadian * ${ }^{\mathbb{D}}$ and \\ Ashkan Ghanbarzadeh-Dagheyan (D) \\ Department of Mechanical Engineering, Sharif University of Technology, Tehran 11365-11155, Iran; \\ anooshegh@gmail.com (A.G.-D.); ashkan.ghanbarzade@gmail.com (A.G.-D.) \\ * Correspondence: ahmadian@sharif.edu
}

Received: 2 November 2019; Accepted: 11 December 2019; Published: 3 January 2020

\begin{abstract}
In this paper, as an application in biometrics, the electrical capacitance of normal and cancerous blood samples is experimentally determined in order to test the null hypothesis that the electrical capacitance of the two samples differs. The samples taken from healthy donors and patients diagnosed with different types of hematologic cancer are examined by a cylindrical capacitor with blood as its dielectric. The capacitance of these samples is measured at room temperature and a single frequency of $120 \mathrm{~Hz}$, well below the frequency where $\beta$-dispersion starts, using a simple LCR meter device. The measurements indicate that the capacitance of the blood increases under applied electric field for a short period of time and asymptotically reaches its steady-state value. The measured values for the healthy group agreed with previous data in the literature. By the use of the unpaired two-tailed T-test, it is found that cancerous blood has higher values of capacitance when compared to normal samples $(p<0.05)$. The reasons that might lead to such alterations are discussed from a biological perspective. Moreover, based on correlation calculations, a strong negative association is observed between blood capacitance and red blood cell (RBC) count in each group. Furthermore, sensitivity (SE) and specificity (SP) analysis demonstrates that for a threshold value between 15 and 17 for the capacitance value, both SE and SP are 100\%. These preliminary findings on capacitance values may pave the way for the development of inexpensive and easy-to-use diagnosis tools for hematologic cancers at medical facilities and for in-home use, especially for children.
\end{abstract}

Keywords: blood characterization; cancer detection; biometrics; biosensor; pediatric cancer

\section{Introduction}

The electrical properties of human blood, including its cells, can be representative of abnormalities in the body. Hence, the investigation of these properties has received much interest during the last few decades. Both the electrical and mechanical properties of blood are functions of the combined effects of hormones, vitamins, ions, glucose, bacteria, proteins, oxygen, and other chemicals that compose it. Diseases are usually accompanied by changes in the level or function of these factors, which, in turn, could alter the electrical properties of their environment. Hence, knowledge of these properties can open up new avenues for the prognosis and treatment of different diseases, as well as for understanding biological processes on microscopic and macroscopic levels.

Several methods including biological impedance, dielectric, admittance, conductance, and light transmission measurements have been introduced to correlate electrical characteristics to the blood behavior. In a review by $\mathrm{Xu}$ et al. on impedance techniques for live biological cells, three main methods were identified: (1) impedance flow cytometry, (2) cell substrate impedance sensing, and (3) impedance 
spectroscopy [1]. All these methods are label-free and non-invasive. The first two perform a single frequency impedance measurement, while the third one measures impedance at multiple frequencies, yielding more information about the electrical properties of cell parts. However, frequency sweeping takes time, and for applications where quick characterization is desirable (as is the case of this study), this method is not preferable. Impedance flow cytometry is the method of choice for cells in suspension, as in the blood or in a microfluidic device.

Besides the above methods, classical impedance measurement of blood using electrodes or probes was reported in [2-4] and more recently in [5,6]. The dielectric properties of blood can be extracted from the measured impedance data. These studies usually involve measuring impedance at multiple frequencies [4,7] and have been used to monitor the short term behavior of blood (e.g., coagulation [2]) or its long term properties (e.g., glucose content [6] or viscosity [4]). A triple frequency measurement method was proposed by Zhao et al. to collect resistivity and capacitance data from the blood simultaneously [3]; however, as will be shown in this study, when only permittivity evaluation is intended, a single frequency measurement would suffice.

Some studies have focused on single cell, dielectric characterizations to monitor pathological behavior. For instance, How-Wang et al. employed a microfluidic device and an impedance spectroscopy system to study the electrical properties of HeLa cells (an immortal human cell line) including their permittivity and conductivity under a specified range of frequencies and voltages [8]. Accompanying the experimental results with simulations, they were able to devise a model for permittivity and conductivity values for these cells at different frequencies and voltages. Impedance measurement has been applied in the detection of tumor cells as well. Nwankire et al. measured the impedance of a group of ovarian cancer cells (SKOV3) using an electrochemical lab-on-a-disc device. They applied different AC amplitudes to measure impedance changes during cell capture [9].

Dielectric and other passive electrical properties of different blood cells and their components, such as erythrocytes, cultured cells, lipid vesicles, enterochromaffin cells, and glucose have been also investigated. In these studies, the properties of the aforementioned substances at various radio frequencies and their dependence on blood medium, its composition, and the shapes of its cells have been examined [10-14]. Dielectric techniques are also powerful tools for studying multiple stages of a cell's lifecycle (mitosis, differentiation,traumatic death, apoptosis) [15].

Dielectric measurements are sometimes carried out by concentrating on blood conductivity rather than permittivity. For example, Baskurt et al. monitored the changes of conductance by recording electrical conductance and light transmission signals for red blood cells (RBCs) to study the effect of RBC aggregation during blood flow stoppage [16]. They were able to show that the time responses of conductance and light transmission were similar during the course of their experiment. Jung et al. also worked with conductance as their measured parameter to characterize hematocrit, which could be a marker for cardiovascular diseases [17]. They defined a specific bipolar, square-wave voltage signal and a blood flow rate in which the unwanted effects of erythrocytes, plasma, and blood cells on the conductivity and capacitance of whole blood were minimized. In such a condition, they were able to measure the hematocrit ratio of RBCs' volume to the whole blood volume more precisely, using a single frequency.

As can be deduced from the works considered up to this point, some studies focused on individual cells, while others treated the blood as a whole. In the former (microscopic) approach, one of the limitations that exists in the way of blood study is associated with the microscopic description of the blood response to the electric field due to the complex network of micro-organs within it. Hence, most of the time, the later (macroscopic) approach is exploited to inspect the net results of the phenomena occurring on microscopic levels. It is important to mention that the electrical properties of blood, besides its main factors, also depend on the external environment conditions like temperature and applied frequency, as well as lighter particles (compared to RBCs and white blood cells (WBCs) and chemical substances) [18-20].

On frequency dependency, Schwan considered the electrical properties of blood for a relatively wide range of frequencies and discussed the reasons for the dispersive trend of some of these properties 
within three regions of relaxation [21]. The author identified three major dispersions in biological tissue on the permittivity-versus-frequency plot at different frequencies: $\alpha, \beta$, and $\gamma$, as well as a minor dispersion, $\delta$. This categorization of dispersion for human tissues, at a macroscopic level, is still in use today [22], and it is not yet well known why blood does not exhibit $\alpha$-dispersion.

The studies that have been done based on dielectric properties exploited disparate methods like dielectric spectroscopy (as mentioned above), non-equilibrium thermodynamic nanosecond, and Cole-Cole relaxation modeling to investigate the behavior of whole blood, such as its dependence on hematocrit value, polarization effects, its properties in different dispersion regions, and the poration and swelling of erythrocytes [13,23-25]. As a case in point, in order to demonstrate the relation between the conductivity of blood and erythrocyte concentrations, Hirsch et al., along with other colleagues, built and tested an apparatus for the measurement of conductivity. Furthermore, they showed that measuring the conductivity of cells by an appropriate design could overcome the challenges that exist in determining a true and agreed value for the whole blood conductance [26].

Applications of the electrical characterization of blood are multifarious. For example, Gong et al. introduced an impedimetric technique that was useful for detecting internal bleeding of the eye [27]. In 2010, Abdalla et al. used a microfluidic device and compared the electrical behavior of normal and diabetic blood samples from 20 diabetic patients and 10 healthy subjects [28]. A difference was shown both in the electric dispersion and relaxation time of the two types of blood samples, showing how the diabetic status of blood is reflected in its dielectric behavior.

The present contribution aims to give a simple biometric approach for measuring the capacitance of blood samples for the application of pediatric cancer detection. This method is comparable with classical impedancemetry techniques [2-4], but what is novel in this work, in addition to its unprecedented application, is the use of a cylindrical capacitance for a simple conversion from impedance to capacitance and, then, to the dielectric constant. As shown in [28] and other similar works, at low frequencies, the difference between the dielectric constant of normal and abnormal blood is more significant than that at high frequencies. Thus, at low frequencies, permittivity may be used as a criterion to differentiate a healthy and normal condition from an abnormal (cancerous) one. Subsequently, as a fast and read-to-apply method, the measurements in this work are intentionally carried out at a single frequency $(120 \mathrm{~Hz})$, well below the first dispersion region, as reported in [23], and where the associated permittivity values lead to large enough capacitance values, measurable by the inexpensive LCR device used to collect the data. It will be shown that abnormal samples consistently have higher dielectric constant values at the selected frequency.

Studies with a similar idea have been done in recent years for adult patients with lung and breast cancer [29-32]. The idea presented in this work has several novelties and advantages over the previous ones: (1) it focuses on hematologic cancers (not reported before) in children; (2) it macroscopically measures whole blood (not blood components) at low frequencies (which enables the development of inexpensive systems); and (3) it offers a simple, self-made device (a cylindrical capacitor) to carry out the measurements. The rest of the paper is outlined as follows: Section 2 describes the devised capacitor and the experiment procedures; Section 3 presents the results and their analysis; Section 4 is dedicated to discussing the reasons behind electrical changes in cancer cells and the study limitations; finally, in Section 5 , the findings of this study are concluded, and the next steps are outlined.

\section{Materials and Methods}

In this section, the experiment layout, the experimental method, and the collected data are presented.

\subsection{Setup}

A cylindrical capacitor was built to measure the capacitance of the samples as follows: Two acrylic cylinders with diameters of $a=1.5 \mathrm{~cm}$ and $b=2.1 \mathrm{~cm}$ and equal heights of $h_{0}=1.5 \mathrm{~cm}$ were concentrically pasted to a wooden base using chloroform. As chloroform is a strong solvent, it melted and welded the wood and acrylic. In this way, a precise sealing was achieved that guaranteed no blood 
leakage from the device. Copper sheets of $0.1 \mathrm{~mm}$ in thickness $(h=1 \mathrm{~cm})$ were attached to the inside of the outer cylinder and the outside of the inner cylinder via a commercial adhesive ("123" glue) to make them conductive. In the final stage, thin wires were brazed on copper sheets. The built capacitor and a 3D model of it are shown in Figure 1. According to Gauss's law, such a cylindrical capacitor has a capacitance of: [33]

$$
C=\frac{2 \pi k \epsilon_{0} h}{\ln (b / a)}
$$

in which $k$ is the relative permittivity (or dielectric constant) of the dielectric medium, $\epsilon_{0}$ is the vacuum permittivity, and $h, a$, and $b$ are defined above. This formula can be used to find the relative permittivity of different blood samples (i.e., $k=\frac{C \ln (b / a)}{2 \pi \epsilon_{0} h}$ ) so that they can be compared with the values reported in the literature.

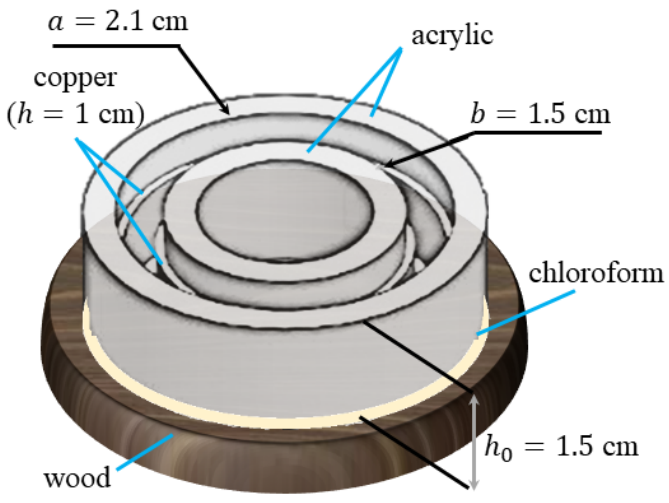

(a)

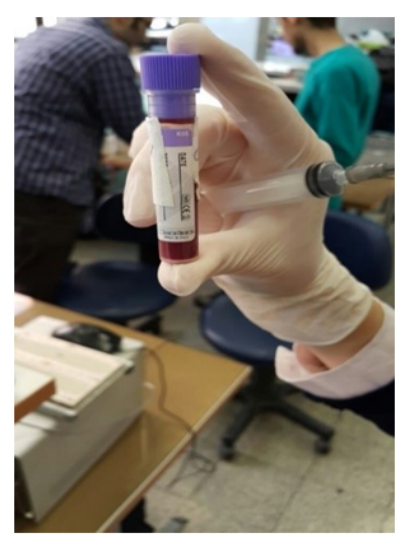

(b)

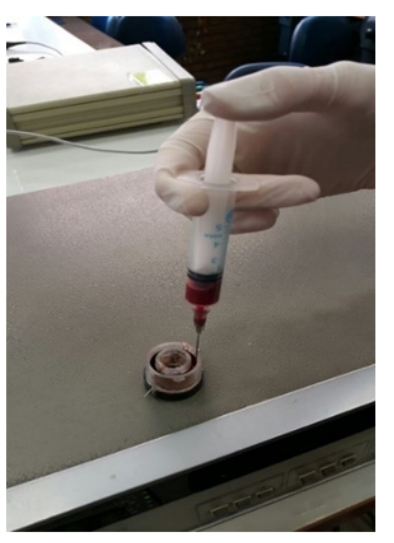

(c)

Figure 1. (a) Schematic model of the designed device and the main dimensions. (b) Two cubic centimeters (cc) of blood samples in an EDTA tube. (c) Cylindrical capacitor with a volume of two cc and collected blood samples as its dielectric material.

\subsection{Experiment and Data Collection}

Samples were obtained from 20 children-12 cancer patients and 8 healthy subjects-between 8 and 18 years old. None of the cancer patients had started treatment at the time of blood draw, and thus, in this way, any possible effect of chemotherapy drugs on blood was avoided. The parents of all the subjects were informed and consented to the use of blood for research. The samples were well shaken and then injected into the device via a syringe (Figure 1c). Afterwards, wires were connected to a digital LCR meter. The circuit type was set to auto mode (series) at a frequency of $120 \mathrm{~Hz}$ (Figure 2). Initially, the capacitance of distilled water was measured at $25{ }^{\circ} \mathrm{C}$ as a reference. This number was equal to $1.1 \mu \mathrm{F}$, which, according to Equation (1), is equivalent to a dielectric constant of $4.43 \times 10^{5}$, in agreement with the values reported in [34], at very low frequencies. For samples, capacitance values were read at intervals of $5 \mathrm{~min}$. These numbers are shown in Table 1 for 12 abnormal (Group A) and 8 normal (Group B) samples. The samples of patients diagnosed with acute lymphocytic leukemia (ALL) are distinguished with asterisks beside their associated number. In Figure 3, the diagram of capacitance value versus time is represented. As observed, after passing $15 \mathrm{~min}$, the amounts reached relatively steady numbers and the variations remarkably decreased. Therefore, these numbers were considered as the final capacitance value for each sample. An exponential curve was fitted to each dataset for better representation of the behavior of capacitance value changes. 


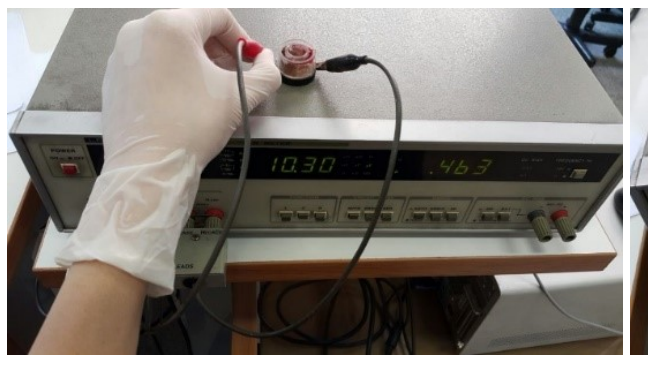

(a)

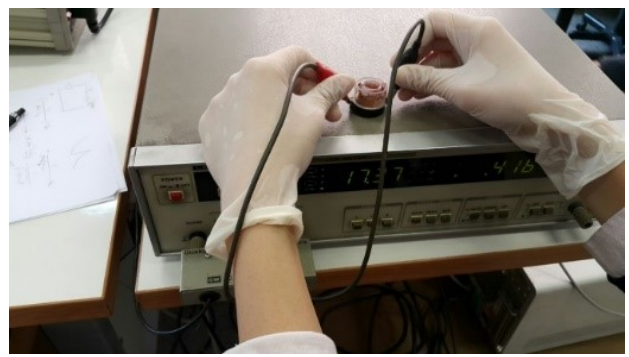

(c)

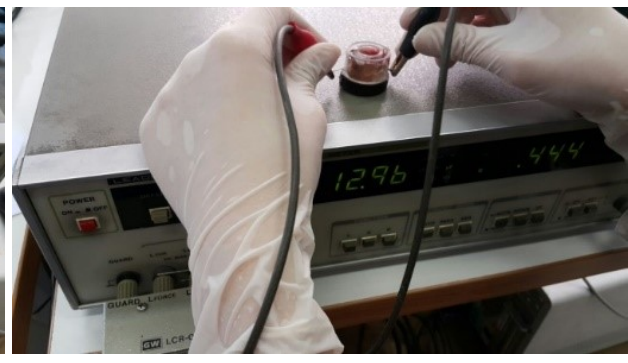

(b)

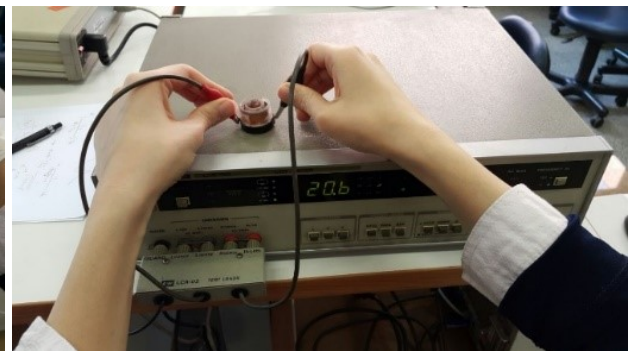

(d)

Figure 2. Capacitance measurement of a cancerous blood sample (Sample \#7 in Table 1; note the values on the screen). (a) At the start time of the experiment; (b) after $5 \mathrm{~min}$; (c) after $10 \mathrm{~min}$; (d); after $15 \mathrm{~min}$ and later on.

Table 1. Capacitance values of the studied blood samples alongside with their blood factors extracted from the complete blood count (CBC) test. The asterisk besides the sample numbers indicates the samples with acute lymphatic leukemia (ALL). Legend: \#: sample number, A: cancerous sample group, B: normal sample group, C: capacitance, $\mathrm{k}$ : dielectric constant, F: female, and M: male.

\begin{tabular}{|c|c|c|c|c|c|c|c|c|c|}
\hline$\#$ & Sex & $\begin{array}{c}\mathrm{RBC} \\
\left(\times 10^{3} \mu \mathrm{L}\right)\end{array}$ & $\begin{array}{c}\text { WBC } \\
\left(\times 10^{6} \mu \mathrm{L}\right)\end{array}$ & $\begin{array}{c}\text { PLTs } \\
\left(\times 10^{3} \mu \mathrm{L}\right)\end{array}$ & $\begin{array}{c}\mathrm{C}(\mu \mathrm{F}) \\
\text { at } t=0\end{array}$ & $\begin{array}{c}\mathrm{C}(\mu \mathrm{F}) \\
\text { at } t=5 \mathrm{~min}\end{array}$ & $\begin{array}{c}\mathrm{C}(\mu \mathrm{F}) \\
\text { at } t=10 \mathrm{~min}\end{array}$ & $\begin{array}{c}\mathrm{C}(\mu \mathrm{F}) \\
\text { at } t=15 \mathrm{~min}\end{array}$ & $\begin{array}{c}k \\
\left(\times 10^{6}\right)\end{array}$ \\
\hline \multicolumn{10}{|l|}{ A } \\
\hline${ }^{*} 1$ & F & 3.36 & 16.35 & 30 & 16 & 17 & 18 & 18.8 & 11.4 \\
\hline$* 2$ & $\mathrm{M}$ & 3.11 & 23.5 & 7 & 11 & 18 & 23.3 & 27.2 & 16.4 \\
\hline$* 3$ & $\mathrm{M}$ & 3.13 & 2.2 & 26 & 11.5 & 20.8 & 24.5 & 26.3 & 15.9 \\
\hline${ }^{*} 4$ & $\mathrm{~F}$ & 3.89 & 4.9 & 18 & 11.7 & 19.4 & 23 & 25.5 & 15.4 \\
\hline$* 5$ & F & 3.73 & 5.9 & 9 & 17.7 & 18.3 & 19 & 20.3 & 12.3 \\
\hline *6 & $\mathrm{M}$ & 3.8 & 31.2 & 49 & 7 & 18.3 & 21.5 & 22.2 & 13.4 \\
\hline$* 7$ & M & 3.62 & 3.9 & 14 & 10.3 & 12.9 & 17.3 & 20.6 & 12.4 \\
\hline 8 & $\mathrm{~F}$ & 4.63 & 6.7 & 241 & 12.7 & 15.2 & 16.8 & 18 & 10.9 \\
\hline 9 & F & 5.45 & 12.6 & 183 & 15.9 & 16.7 & 16.8 & 17.1 & 10.3 \\
\hline 10 & $\mathrm{M}$ & 4.23 & 5.8 & 285 & 16.1 & 16.9 & 17.2 & 18.4 & 11.1 \\
\hline 11 & $\mathrm{M}$ & 4.18 & 8.2 & 166 & 9 & 18.4 & 19.7 & 21.7 & 13.1 \\
\hline 12 & F & 5.18 & 6.2 & 164 & 13 & 22.2 & 24.4 & 25 & 15.1 \\
\hline \multicolumn{10}{|l|}{ B } \\
\hline 13 & F & 4.52 & 6.1 & 201 & 5.7 & 7.7 & 10 & 10.4 & 6.3 \\
\hline 14 & $\mathrm{M}$ & 4.64 & 9.1 & 286 & 1.5 & 4.4 & 6.9 & 8.4 & 5.1 \\
\hline 15 & M & 5.71 & 11.4 & 243 & 4.4 & 7.8 & 9.2 & 10.4 & 6.3 \\
\hline 16 & $\mathrm{M}$ & 4.57 & 5.5 & 294 & 1.7 & 4.8 & 6.8 & 9 & 5.4 \\
\hline 17 & $\mathrm{~F}$ & 4.4 & 5.8 & 262 & 6.1 & 6.9 & 7.7 & 8.5 & 5.1 \\
\hline 18 & $\mathrm{~F}$ & 4.75 & 8.6 & 211 & 9.5 & 10.2 & 10.7 & 11.3 & 6.8 \\
\hline 19 & $\mathrm{M}$ & 5.19 & 6 & 220 & 2.1 & 10.8 & 11.8 & 12.8 & 7.7 \\
\hline 20 & $\mathrm{M}$ & 3.91 & 8.7 & 123 & 12.1 & 12.8 & 13.8 & 14.6 & 8.8 \\
\hline
\end{tabular}




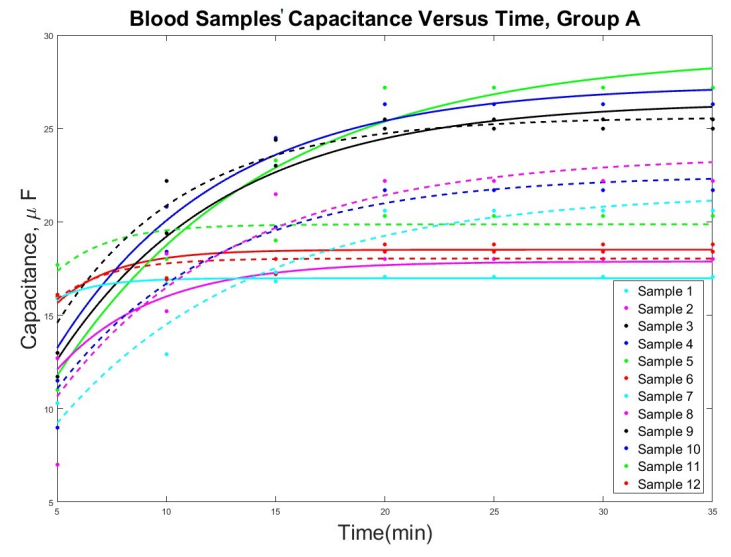

(a)

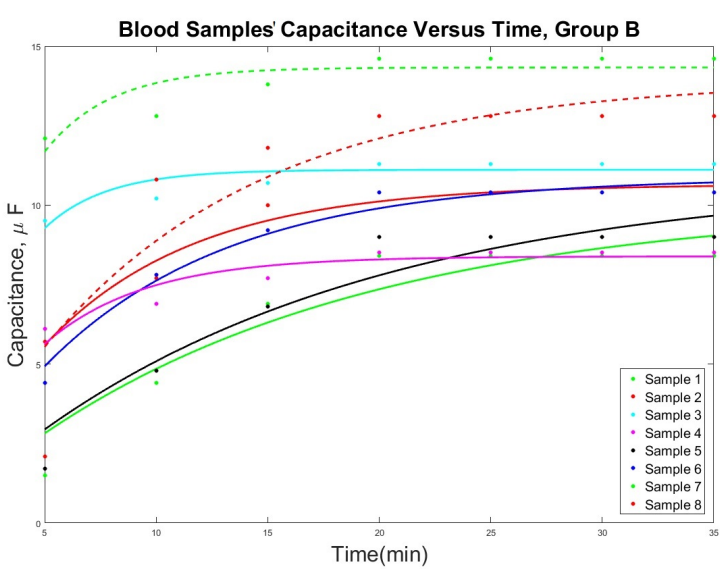

(b)

Figure 3. Diagrams of the capacitance versus time for the examined (a) cancerous (Group A) and (b) normal (Group B) samples. The plots were fitted to the data using MATLAB's "cftool" with a general exponential equation. As can be observed, there is a clear difference between the two groups in the range of steady-state capacitance values.

\section{Results}

Referring to Table 1, when capacitance values were cross-compared, it was seen that the final capacitance of each normal sample was lower than that of each cancerous sample. Furthermore, these numbers converged to approximately specific amounts between 8 and 15 . On the other side, cancerous blood samples indicated higher capacitance values with a convergence range of 17 and 27. One can observe the difference in the significance of the numbers associated with healthy and cancerous samples. To prove that these two datasets were significantly different, an unpaired two tailed T-test was carried out, and it was shown that when the 12 abnormal and 8 normal samples were considered, the $p$-value was close to zero $\left(\approx 2 \times 10^{-7}\right)$, well below 0.05 . The same was true when only ALL samples were compared with normal samples $(p=0.0005<0.05)$. It is worth noting that the obtained dielectric constants at $120 \mathrm{~Hz}$ (last column of Table 1) for the healthy blood samples agreed with the values reported in the literature [23].

Now that it has been shown that there is a significant difference between the two groups, a sensitivity-and-specificity analysis can be conducted. In order to do that, first, one must set a threshold $\gamma$ (or gold standard) for the value of the capacitance such that for all $C_{f}>\gamma$, with $C_{f}$ denoting the final value of capacitance, a cancerous diagnosis can be made, and else, the blood can be identified as non-cancerous. The definitions of sensitivity (SE) and specificity (SP), respectively, are [35]:

$$
\begin{aligned}
& S E=\frac{T P}{T P+F N}, \\
& S P=\frac{T N}{F P+T N},
\end{aligned}
$$

where TP, TN, FP, and FN denote true positive, true negative, false positive, and false negative, in order. Based on the results in Table 1, for any $\gamma \in[1517]$, both SE and SPwere $100 \%$. For a select number of other $\gamma$ values, Table 2 shows the respective SE and SP values. A higher bound for the capacitance of the cancerous samples and a lower bound for the capacitance of the non-cancerous samples cannot be determined before more data on a wide variety of cancer types is collected.

As for sex, the same T-test analysis for males and females revealed that for the whole sample set, Group A, and Group B, respectively, p-values were equal to $0.32,0.23$, and 0.40 . These numbers clearly show that the capacitance value was not associated with sex. In accordance with a previous report on children and adolescents [36], the mean value of RBC count in female subjects was less than that of 
male subjects for the healthy group. The same was true for the patient group: Group A, males: 4.15, females: 3.90; Group B, males: 4.80, females: 4.56 .

Table 2. Sensitivity (SE) and specificity (SP) analysis on the data presented in Table 1 for different values of $\gamma$ (gold standard).

\begin{tabular}{cccccccc}
\hline$\gamma$ & $\begin{array}{c}\text { Corresponding } \\
k\left(\times \mathbf{1 0}^{-\mathbf{6}}\right)\end{array}$ & TP & FN & TN & FP & SE & SP \\
\hline $15-17$ & $9-08-10.28$ & 12 & 0 & 8 & 0 & $100 \%$ & $100 \%$ \\
18 & 10.9 & 11 & 1 & 8 & 0 & $92 \%$ & $100 \%$ \\
20 & 12.09 & 8 & 4 & 8 & 0 & $67 \%$ & $100 \%$ \\
22 & 13.30 & 5 & 7 & 8 & 0 & $42 \%$ & $100 \%$ \\
14 & 8.46 & 12 & 0 & 7 & 1 & $100 \%$ & $88 \%$ \\
12 & 7.26 & 12 & 0 & 6 & 2 & $100 \%$ & $75 \%$ \\
10 & 6.04 & 12 & 0 & 3 & 5 & $100 \%$ & $38 \%$ \\
\hline
\end{tabular}

Though the goal of this study was to merely compare the capacitance values of cancerous and healthy blood samples, it would be interesting to see whether the amount of blood factors was related to the value of the measured capacitance or not. In Figure 4, the amounts of RBCs, WBCs, and platelets (PLTs) extracted from complete blood count (CBC) are presented. These blood factors are the most important indices for the diagnosis of certain types of cancer like leukemia. They can be directly affected by cancerous mutations especially in later stages. RBCs account for $42-45 \%$ of blood volume, and WBCs occupy $1 \%$ of it. WBCs, as immune cells, in spite of their low volume percentage, have a critical role in cleansing the body by attacking and absorbing any invading agent. Thus, they can experience unbalanced conditions facing cancer cells.
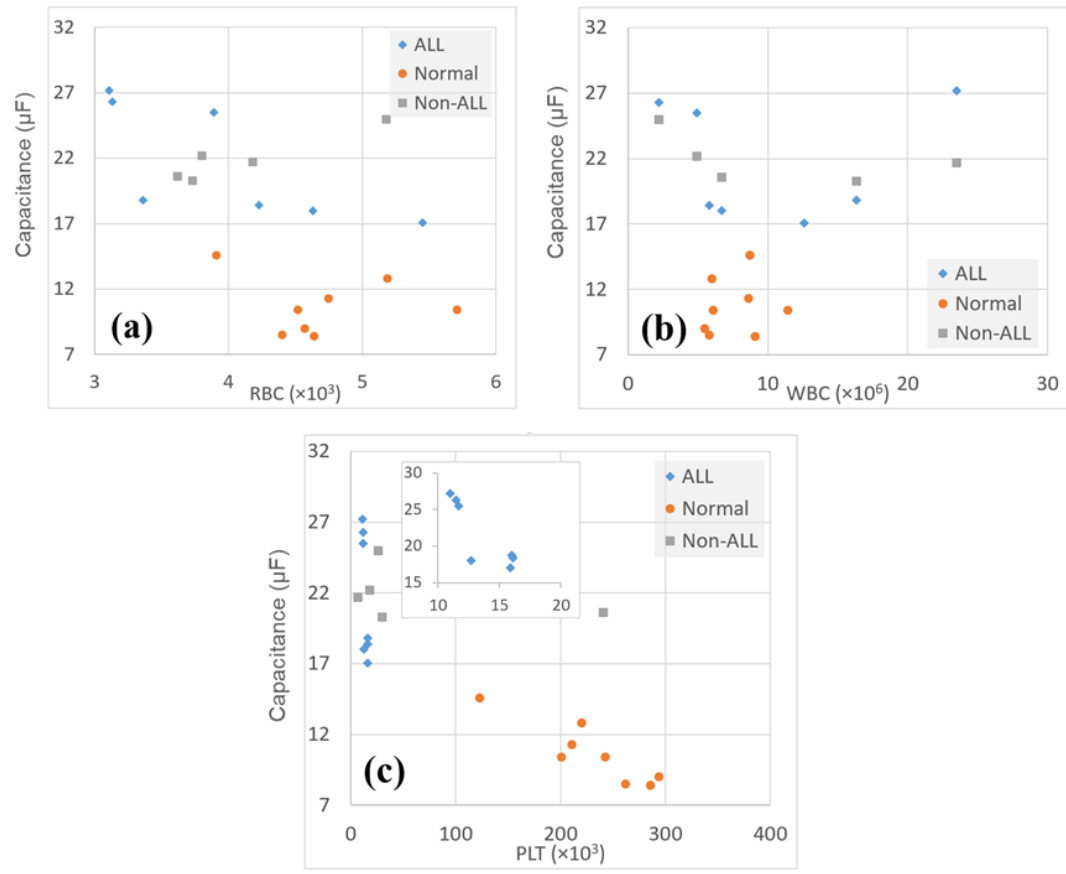

Figure 4. Diagrams of the three main blood factors of the examined samples, versus the measured capacitance. (a) White blood cells (WBCs). (b) Red blood cells (RBCs). (c) Platelets (PLTs). The inset in (c) depicts the values for ALL samples from a closer view. The samples from patients whose cancer was diagnosed to be other than ALL (Subjects 8-12 in Table 1) are denoted on the plots by "non-ALL".

However, the data showed that the increase in capacitance was not associated with the amounts of WBCs, most probably due to their small numbers relative to RBCs. The average and standard 
deviation of these factors for both groups are calculated in Table 3. The standard deviation for WBC and PLT data was considerably large relative to their mean values, and thus, the means of these two factors cannot be meaningfully compared for normal and abnormal samples. However, for the RBC data, the standard deviation was meaningful, showing that normal samples had a slightly higher RBC mean value than cancerous samples. This was more significant when ALL samples were considered separately, as shown in the second column of Table 3. The ratio between the mean RBC values of abnormal samples and normal samples was 0.85. This number was 0.75 when only ALL samples were considered, and this was consistent with the low hemoglobin count observed in patients diagnosed with leukemia.

The capacitance mean values for all samples are also calculated in Table 3, and as can be observed, the ALL samples, which had lower mean RBC counts than those of normal samples, had higher mean capacitance values compared to normal samples. Moreover, the correlation between capacitance values and each factor was calculated, and it was found that capacitance values and both RBCs and PLTs were significantly associated in each group. Still, as PLT data had a large standard deviation, the observed correlation might not be reliable. For equal amounts of RBCs (for example, Sample \#8 and Sample \#14 or Sample \#4 and Sample \#20), the capacitance value was still larger for the cancerous blood. Since the number of samples was limited, drawing a conclusion about the relationship between RBCs and the capacitance of blood samples might be difficult at this point, even though the correlation values exhibited a strong association. More investigation is required to test the relation between the two factors.

As mentioned, the data of WBCs and PLTs appeared to be sporadic, and therefore, a relation between their counts and the condition of blood samples cannot be built. For the abnormal samples tested in this experiment, these factors varied from 2.2 to 31.2 and 7 to 285 , respectively. The normal samples had a wide range of values, 5.5 to 11.4 and 123 to 294, respectively, as well. Though high data heterogeneity is generally not desirable, it could have a positive side here, because, it suggests that the change in blood capacitance might not necessarily relate to WBC and PLT counts. It should be noted that capacitance values may be affected by the presence of lighter compounds (hormones, antibodies, vitamins, bacteria) or free radicals in the blood as well [28].

Despite the uncertainty in the observed correlations, the first finding, that is the larger capacitance values for cancerous blood samples, when compared to normal ones, was strong and verified the null hypothesis.

Table 3. The mean and standard deviation value of the blood factors for normal, ALL, and cancerous blood samples. The correlation values between capacitance and individual blood factors are also listed.

\begin{tabular}{cccc}
\hline Parameter & $\begin{array}{c}\text { Cancerous } \\
\text { Samples }\end{array}$ & $\begin{array}{c}\text { ALL } \\
\text { Samples }\end{array}$ & $\begin{array}{c}\text { Normal } \\
\text { Samples }\end{array}$ \\
\hline RBCs & $4.026 \pm 0.075$ & $3.520 \pm 0.320$ & $4.711 \pm 0.538$ \\
Correlation with Capacitance & -0.44 & -0.51 & -0.15 \\
WBCs & $10.621 \pm 8.848$ & $12.564 \pm 11.305$ & $7.650 \pm 2.116$ \\
Correlation with Capacitance & -0.072 & -0.073 & -0.15 \\
PLTs & $99.333 \pm 101.564$ & $21.857 \pm 16.622$ & $230 \pm 55.001$ \\
Correlation with Capacitance & -0.53 & -0.77 & -0.90 \\
Capacitance & $21.756 \pm 3.497$ & $22.986 \pm 3.319$ & $10.675 \pm 2.177$ \\
\hline
\end{tabular}

\section{Discussion}

In this section, an effort is made to identify the possible reasons for the observed change in the dielectric properties of cancerous blood samples, by referring to previous research works. This comprehensive investigation is beyond the association observed between RBC count and capacitance values, focusing mostly on microscopic mechanisms that might explain the conspicuous, macroscopic 
difference between the capacitance (or dielectric) values of affected and healthy blood. Further, the limitations of this study, by reference to multiple research studies in the field of pediatric cancer, are discussed.

\subsection{Potential Mechanisms behind the Study Observations}

Generally, when an abnormality emerges in the body, it reveals itself as several changes in cell mechanisms, which, in turn, cause variations in blood properties. In each cell, there are electrical components that together build up a coherent circuit [21]. These components enable cells to regulate and control the transduction of chemical energy and other processes. For example, the cell membrane and its receptors can be viewed as transducers, inductors, and resonators of the cell. DNA acts as an inductor and resonator, and organelle membranes are capacitors $[37,38]$. Furthermore, membrane protein complexes and liquid crystal proteins are considered as tuning circuits and semiconductors, respectively [39].

When these electrical parts work correctly and in harmony, the cell exhibits normal behavior. However, changes in the chemical substances of intra- or extra-cellular environments, as well as the disturbance in electrical charges can lead to cell mutation, which, in turn, causes malfunction or disease. Therefore, cancerous cells are transformed organs of distinct characteristics, which are discussed more thoroughly in the following [40,41].

The flow of inborn electrical currents in the body is used to launch, regulate, and control the tissues. These currents instigate primitive cells to differentiate into the different cells that are required for normal body function, such as osteoblasts, erythrocytes, monocytes, megakaryocytes, and chondrocytes. To do so, the primitive cells must have a normal membrane potential and several essential nutrients [42-46].

One feature of cancerous and injured cells is their lower cell membrane potential compared to that of normal cells. Cell membrane potential controls membrane permeability to nutrients and is responsible for initiating energy production and macromolecular synthesis. The membrane potential of healthy cells is in the range of -60 to $-100 \mathrm{mV}$. During some stages of the cell lifecycle like DNA synthesis, this potential can temporarily wane (to $-15 \mathrm{mV}$ ), but in cancer cells, this reduction is perennial [47-49].

A decreased potential can make the membrane more permeable to certain substances that are not found normally in healthy cells. For example, some constitutive minerals of the cytoplasm, such as potassium, magnesium, calcium, and zinc, can migrate from the cell, while, on the other side, sodium and water (especially unstructured water) can freely flow into the cell and accumulate in the intracellular space. In this condition, cell proteins may prefer to associate with sodium rather than potassium, and sodium content in the intracellular space may act as a trigger for mitosis (cell division). Moreover, these proteins become incapable of structuring the water that has entered the cell. The concentration of these minerals and the electrical potential of the membrane are correlated, but it is not quiet known which one affects the other first [50].

Alterations in membrane potential also affect the metabolic function of the cell and the energy mechanism it uses. Cells obtain their energy from food and air by catalyzing enzymes, chemical reactions, and oxidation of fats, proteins, and carbohydrates. Besides, they produce energy by oxygen dependent or aerobic enzymes. Throughout the chemical reactions that occur in the respiratory chain (electron transport chain), a molecular motor is turned on that converts adenosine diphosphate (ADP) to adenosine triphosphate (ATP) [51]. In cancerous cells, this normal energy synthesis is disrupted. Consequently, they use fermentation (glycolysis), which is a primary anaerobic type of energy production and a less efficient one. The proliferation of tumor cells is strongly encouraged by this change. Pyruvate dehydrogenase, the enzyme that is responsible for determining whether energy is derived by the aerobic or anaerobic pathway, is transformed in cancer. Like what was said about membrane potential changes, the aerobic energy mechanism of healthy cells is only temporarily switched to anaerobic during wound healing, but this alteration is permanent in cancer cells [52-55]. 
In addition to the aforementioned factors, hypoxic and acidic microenvironments play critical roles in metabolic changes. Such environments make cells vulnerable to mutations and genetic instabilities. Accordingly, some genes are activated, and subsequently, changes occur in metabolic reactions. One of the reasons for different responses of the same tumors or cancerous cells to identical treatments can be traced back to this phenomenon. Since some cells still use the normal energy mechanism, while others do not, a heterogeneous amalgam of cells exists in the blood. Hence, their behavior in response to external stimuli can differ [56-59].

As a result of these changes, cancer cells have different contents of fat, sterol, enzyme, protein, and cytoplasm, as well as dissimilar cytoskeleton structures and, even, membrane receptors. Some of their proteins have the arrangement of embryonic cells having different bindings. Hence, cancer cells become independent, and somehow detached, from the signals sent out by the extracellular matrix (ECM) for growth control and normal tissue formation [60]. ECM comprises an electrical field that oscillates in response to proteoglycans to send this electrical signal. Furthermore, ECM receptors work like antennas to receive particular frequencies of electromagnetic energy, which enables this matrix to exert growth factor inhibition [61]. In a healthy state, ECM has a certain amount of negative charge whose magnitude depends on the content of ions, minerals, and sialic acid residues [62].

Cancer cells ignore ECM, and instead, using some types of glycoproteins and antigens, they express their own growth factor. Hence, they have disrupted electric fields and unintegrated signals with more negative charges (due to overexpression of sialic acid molecules) on their surface and outside of the cells, leading to different interactions with the environment. Extra negative charges of the exterior surface, which depolarize the cell membrane, is another reason for lower membrane potential of cancer cells [63].

On the other hand, as a reaction to this abnormal condition, cells release more toxins into ECM, making it more acidic, and ECM is forced to create areas of higher resistance to protect itself. However, this increased resistivity hinders the flow of endogenous electric currents to reach these areas and eventually interferes with the process of healing. What is more, a decrease in electrical flow causes lower membrane capacitance $[64,65]$.

To sum up, electrical properties of a tissue correspond to electron availability, tissue acidity, hypoxia, the presence of antioxidants (electron donors), water content, and the electrophilic compounds existing on the cell membrane and in the ECM. In all cancer cells, the system of electron transfer is damaged. As an electrical property, the conductivity of a tissue is a function of the mineral concentration of cells, the types of these minerals, oxygen level, ECM fluid and state, intra- or extra-cellular $\mathrm{PH}$, water content, the ratio of the structured to unstructured water, amount of negative charge on the membrane and its composition, and the presence of free radicals, toxins, and metals in the cell. For instance, it has been reported that the electrical conductivity and permeability of cancer cells are higher than normal cells [66].

These characteristics might explain how applying electrical currents may be effective in reversing some mutated cells back to their normal, healthy status. Applying electric current can increase the activity of the immune system, subdue the impaired DNAs produced by cancer cells, and change membrane potential and taking up of nutrients. Some techniques, such as scientifically supported herbal treatments, phototherapy, and microcurrent treatment, release free electrons in the body that can react with the free radicals and protect cells and DNAs from the damage they cause [67-71].

Considering all the previous evidence on the electrical differences between normal and abnormal cells, this paper focused on using the electrical capacitance as an indicator of the electrical changes in cancerous blood samples, on a macroscopic scale. The results of this work are consistent with the evidence presented in the literature in that the electrical properties of normal tissues differ from those of cancerous ones. As mentioned before, other macroscopic approaches have been reported for the detection of cancer in adult patients, with similar findings [29-32]. 


\subsection{Study Limitations}

This study is limited by the low number of blood samples; however, blood studies of this type have been reported in the literature using fewer samples. For instance, Ülgen and Sezdi employed bio-impedance spectroscopy to study the relation between four Cole-Cole parameters and the hematocrit concentration of whole blood, and they utilized blood samples of only ten human subjects [72]. Besides, there are reasons specific to the research at hand, which justifies the mentioned limitation:

1. It is well known that pediatric cancer research, due to nonprofitablity, is, sadly, a greatly underfunded (almost neglected) field of research. A look at many original studies on minor cancer patients reveals that the sample sizes are generally small, as in this study. For example, the authors in [73-75], respectively, had 17, 20, and 28 subjects in their study. Further, in a previous paper by the two authors of the study at hand, only 11 children remained until the end of the study for the experimental and control group, combined [76,77]. This could be due to a lack of adequate funding to conduct large scale studies on children suffering from cancer, as well as the difficulty in recruiting these children in the study.

2. In this research, due to the study design and taking into account the effect of common drugs for cancer therapy, it was necessary to find recently diagnosed cancer patients, in a specified age range, who had not yet gone under any treatment (chemotherapy, radiotherapy, etc.). Besides, among the eligible subjects, it was still required to have the consent of their parents for obtaining blood samples. Considering their situation and the fact that frequent blood draw and injections already cause discomfort for pediatric patients, only one sample was obtained from each eligible patient.

3. This was a proof-of-concept study, aimed at testing a hypothesis, with limited resources, for further, more thorough investigations in the future. Well conducted small scale studies, particularly the ones that do not deal with developing new medical drugs, have the distinct benefit of reporting a new observation or phenomenon. Novel ideas can compensate for the justified shortage of data, as the case reported in [77].

\section{Conclusions}

In this study, a cylindrical capacitor was designed and fabricated to measure the relative capacitance of normal and cancerous blood samples, as a novel and simple idea. The measurements were carried out using an LCR meter device. It was observed that the capacitor, in the case of using cancerous blood samples as the dielectric material, had larger capacitance values than when normal samples were used as its dielectric. An unpaired two tailed T-test analysis also confirmed that the data of two groups, both normal-versus-cancerous and normal-versus-ALL, were significantly different. Sensitivity (SE) and specificity (SP) analysis showed that for a threshold value between 15 and 17 for the measured capacitance of blood, SE and SP were both $100 \%$.

Furthermore, an effort was made to see how blood factors affected the capacitance values. WBCs, RBCs, and PLTs, the three most affected cells in ALL, were extracted from CBC tests. Comparing the amount of capacitance in ALL with other types of cancer indicated that WBCs and PLTs may not have an influence on the studied electrical property, particularly given their high standard deviations, which impedes drawing definite conclusions. Instead, higher values of capacitance in all groups (normal, cancerous, and ALL) were accompanied with lower values of RBC counts, exhibiting strong negative correlations, especially for cancerous samples. Furthermore, the capacitance change might be related to the presence of substances that do not exist in normal blood samples or exist in lower concentrations, such as free radicals.

The noticeable difference observed between capacitance values $(p<0.05)$ may be used as an indicator of abnormal alterations at microscopic levels, such as those caused by cancer. Further investigations are needed to specify the range of capacitance values for each blood sample and to calibrate the device with respect to the various types of blood cancer. Because of the experiment limitations, especially the low number of samples, such calibration was not possible. Having more samples from a wider range of cancer types might make possible the categorization of cancer types 
based on capacitance values, in future studies. By applying some modifications on the dimension and accuracy of this device, as well as using an automatic and more precise tool for measuring the capacitance, the device could be used in an in-home kit for testing the blood. Thus, it would be similar to the kits that are available for blood glucose monitoring, cholesterol, blood pressure, cardio-check, triglycerides, and activated clotting-time measuring tests.

Compared to studies with a similar idea, this research work had distinct novelties since it concentrated on (1) hematologic cancer in pediatric patients, (2) whole blood at a low frequency, and (3) a simple and self-made device that could enable the measurements. Pediatric cancer research is greatly underfunded, and it is hoped that this study will propel and expand investigations in this field.

Author Contributions: Conceptualization, A.G.-D. (Anooshe Ghanbarzadeh-Daghian) and M.T.A.; methodology, A.G.-D. (Anooshe Ghanbarzadeh-Daghian) and M.T.A.; software, A.G.-D. (Ashkan Ghanbarzadeh-Dagheyan); validation, A.G.-D. (Anooshe Ghanbarzadeh-Daghian) and A.G.-D. (Ashkan Ghanbarzadeh-Dagheyan); formal analysis, A.G.-D. (Anooshe Ghanbarzadeh-Daghian) and A.G.-D. (Ashkan Ghanbarzadeh-Dagheyan); investigation, A.G.-D. (Anooshe Ghanbarzadeh-Daghian); resources, A.G.-D. (Anooshe Ghanbarzadeh-Daghian); data curation, A.G.-D. (Anooshe Ghanbarzadeh-Daghian) and A.G.-D. (Ashkan Ghanbarzadeh-Dagheyan); writing, original draft preparation, A.G.-D. (Anooshe Ghanbarzadeh-Daghian); writing, review and editing, A.G.-D. (Anooshe Ghanbarzadeh-Daghian), M.T.A., and A.G.-D. (Ashkan Ghanbarzadeh-Dagheyan); visualization, A.G.-D. (Anooshe Ghanbarzadeh-Daghian); supervision, M.T.A.; project administration, M.T.A. All authors have read and agreed to the published version of the manuscript.

Funding: This research received no external funding.

Acknowledgments: Special thanks to Ghare-Daghi (board certified in pain management and head of the cancer research center) and Fallah Azad (head of the laboratory) at Mahak Charity Organization and Company (oncologist) at Children's Medical Center for their guidelines and cooperation in collecting and preparing the required samples. We would like to thank Iran's National Elite Foundation as well.

Conflicts of Interest: The authors declare no conflict of interest.

\section{Abbreviations}

The following abbreviations are used in this manuscript:

$\begin{array}{ll}\text { ALL } & \text { Acute lymphocytic leukemia } \\ \text { CBC } & \text { Complete blood count } \\ \text { PLT } & \text { Platelets } \\ \text { RBC } & \text { Red blood cell } \\ \text { WBC } & \text { White blood cell }\end{array}$

\section{References}

1. Xu, Y.; Xie, X.; Duan, Y.; Wang, L.; Cheng, Z.; Cheng, J. A review of impedance measurements of whole cells. Biosens. Bioelectron. 2016, 77, 824-836. [CrossRef]

2. Connelly, J.; Buckler, M. The continuous measurement of resistivity and permittivity of human blood plasma during coagulation. Med Biol. Eng. 1975, 13, 523-530. [CrossRef] [PubMed]

3. Zhao, T.X.; Jacobson, B.; Ribbe, T. Triple-frequency method for measuring blood impedance. Physiol. Meas. 1993, 14, 145. [CrossRef] [PubMed]

4. Chang, Z.Y.; Meijer, G.C.; Pop, G. A novel model of blood impedance for indirect viscosity measurement. Proc. Electron., Sozopol, Bulgaria, 22-24 September 2004. Available online: https:/ / ecad.tu-sofia.bg/et/ 2004/Papers/Electronic\%20Medical\%20Equipment/Paper-Zu-yao.pdf (accessed on 13 December 2019).

5. Zhbanov, A.; Yang, S. Electrochemical impedance spectroscopy of blood for sensitive detection of blood hematocrit, sedimentation and dielectric properties. Anal. Methods 2017, 9, 3302-3313. [CrossRef]

6. Pradhan, R.; Mitra, A.; Das, S. Quantitative evaluation of blood glucose concentration using impedance sensing devices. J. Electr. Bioimpedance 2019, 4, 73-77. [CrossRef]

7. Dai, T.; Adler, A. Blood impedance characterization from pulsatile measurements. In Proceedings of the 2006 Canadian Conference on Electrical and Computer Engineering, Ottawa, ON, Canada, 7-10 May 2006; pp. 983-986. 
8. Wang, M.H.; Jang, L.S. A systematic investigation into the electrical properties of single HeLa cells via impedance measurements and COMSOL simulations. Biosens. Bioelectron. 2009, 24, 2830-2835. [CrossRef]

9. Nwankire, C.E.; Venkatanarayanan, A.; Glennon, T.; Keyes, T.E.; Forster, R.J.; Ducrée, J. Label-free impedance detection of cancer cells from whole blood on an integrated centrifugal microfluidic platform. Biosens. Bioelectron. 2015, 68, 382-389. [CrossRef]

10. Asami, K. Dielectric properties of dipicrylamine-doped erythrocytes, cultured cells and lipid vesicles. Bioelectrochemistry 2013, 92, 14-21. [CrossRef]

11. Di Biasio, A.; Cametti, C. Effect of the shape of human erythrocytes on the evaluation of the passive electrical properties of the cell membrane. Bioelectrochemistry 2005, 65, 163-169. [CrossRef]

12. Yoon, G. Dielectric properties of glucose in bulk aqueous solutions: Influence of electrode polarization and modeling. Biosens. Bioelectron. 2011, 26, 2347-2353. [CrossRef]

13. Beving, H.; Eriksson, L.; Davey, C.; Kell, D. Dielectric properties of human blood and erythrocytes at radio frequencies $(0.2-10 \mathrm{MHz})$; dependence on cell volume fraction and medium composition. Eur. Biophys. J. 1994, 23, 207-215. [CrossRef] [PubMed]

14. Bai, W.; Zhao, K.; Asami, K. Effects of copper on dielectric properties of E. coli cells. Colloids Surf. B Biointerfaces 2007, 58, 105-115. [CrossRef] [PubMed]

15. Patel, P.; Markx, G.H. Dielectric measurement of cell death. Enzym. Microb. Technol. 2008, 43, 463-470. [CrossRef]

16. Baskurt, O.; Uyuklu, M.; Meiselman, H. Simultaneous monitoring of electrical conductance and light transmittance during red blood cell aggregation. Biorheology 2009, 46, 239-249. [CrossRef]

17. Jung, J.M.; Lee, D.H.; Kim, K.T.; Cho, Y.I. Determination of hematocrit using on-line conductance cell. Int. J. Heat Mass Transf. 2012, 55, 1836-1843. [CrossRef]

18. Jaspard, F.; Nadi, M. Dielectric properties of blood: An investigation of temperature dependence. Physiol. Meas. 2002, 23, 547. [CrossRef]

19. Sun, L.; Collins, C.; Schiano, J.L.; Smith, M.; Smith, N. Adaptive real-time closed-loop temperature control for ultrasound hyperthermia using magnetic resonance thermometry. Concepts Magn. Reson. Part B Magn. Reson. Eng. Educ. J. 2005, 27, 51-63. [CrossRef]

20. Sigman, E.; Kolin, A.; Katz, L.; Jochim, K. Effect of motion on the electrical conductivity of the blood. Am. J. Physiol. Leg. Content 1937, 118, 708-719. [CrossRef]

21. Schwan, H. Electrical properties of blood and its constitutents: Alternating current spectroscopy. Blut Zeitschrift für die Gesamte Blutforschung 1983, 46, 185-197. [CrossRef]

22. Grimnes, S.; Martinsen, Ø.G. Alpha-dispersion in human tissue. In Journal of Physics: Conference Series; IOP Publishing: Bristol, UK, 2010; Volume 224, p. 012073.

23. Wolf, M.; Gulich, R.; Lunkenheimer, P.; Loidl, A. Broadband dielectric spectroscopy on human blood. Biochim. Biophys. Acta (BBA) Gen. Subj. 2011, 1810, 727-740. [CrossRef]

24. Farsaci, F.; Tellone, E.; Cavallaro, M.; Russo, A.; Ficarra, S. Low frequency dielectric characteristics of human blood: A non-equilibrium thermodynamic approach. J. Mol. Liq. 2013, 188, 113-119. [CrossRef]

25. Zhuang, J.; Kolb, J.F. Time domain dielectric spectroscopy of nanosecond pulsed electric field induced changes in dielectric properties of pig whole blood. Bioelectrochemistry 2015, 103, 28-33. [CrossRef] [PubMed]

26. Hirsch, F.G.; Texter, E.C.; Wood, L.A.; Ballard, W.C.; Horan, F.E.; Wright, I.S.; Frey, C.; Starr, D. The electrical conductivity of blood: I. Relationship to erythrocyte concentration. Blood 1950, 5, 1017-1035. [CrossRef] [PubMed]

27. Gong, C.S.A.; Lei, K.F.; Hwang, Y.S.; Zhang, J.H.; Lei, T.C. Impedimetric detection of whole blood concentration for early detection of intraocular hemorrhage. Microelectron. Eng. 2014, 129, 70-76. [CrossRef]

28. Abdalla, S.; Al-Ameer, S.; Al-Magaishi, S. Electrical properties with relaxation through human blood. Biomicrofluidics 2010, 4, 034101. [CrossRef]

29. Chen, X.; Lv, X.; Wang, H. Lung carcinoma recognition by blood dielectric spectroscopy. Bio-Med. Mater. Eng. 2015, 26, S895-S901. [CrossRef]

30. Batyuk, L.; Kizilova, N. Dielectric Properties of Red Blood Cells for Cancer Diagnostics and Treatment. Acta Sci. Cancer Biol. 2018, 2, 10. Available online: https:/ / www.actascientific.com/ASCB/pdf/ASCB-020079.pdf (accessed on 13 December 2019) 
31. Moqadam, S.M.; Grewal, P.K.; Haeri, Z.; Ingledew, P.A.; Kohli, K.; Golnaraghi, F. Cancer detection based on electrical impedance spectroscopy: A clinical study. J. Electr. Bioimpedance 2018, 9, 17-23. [CrossRef]

32. Huerta-Nuñez, L.; Gutierrez-Iglesias, G.; Martinez-Cuazitl, A.; Mata-Miranda, M.; Alvarez-Jiménez, V.; Sánchez-Monroy, V.; Golberg, A.; González-Díaz, C. A biosensor capable of identifying low quantities of breast cancer cells by electrical impedance spectroscopy. Sci. Rep. 2019, 9, 6419. [CrossRef]

33. Bueno Barrachina, J.M.; Cañas Peñuelas, C.S.; Catalán Izquierdo, S. FEM edge effect and capacitance evaluation on cylindrical capacitors. J. Energy Power Eng. 2012, 6, 2063-2069.

34. Rusiniak, L. Electric properties of water. New experimental data in the $5 \mathrm{~Hz}-13 \mathrm{MHz}$ frequency range. Acta Geophys. Pol. 2004, 52, 63-76.

35. Parikh, R.; Mathai, A.; Parikh, S.; Sekhar, G.C.; Thomas, R. Understanding and using sensitivity, specificity and predictive values. Indian J. Ophthalmol. 2008, 56, 45. [CrossRef] [PubMed]

36. Gligoroska, J.P.; Gontarev, S.; Dejanova, B.; Todorovska, L.; Stojmanova, D.S.; Manchevska, S. Red Blood Cell Variables in Children and Adolescents regarding the Age and Sex. Iran. J. Public Health 2019, 48, 704.

37. Amin, M.; Dey, P. P.; Badkoobehi, H. A complete electrical equivalent circuit model for biological cell. In Proceedings of the 7th WSEAS International Conference on Applied Computer and Applied Computational Science, Hangzhou, China, 6-8 April 2008; pp. 343-348.

38. Sepehri, A. A mathematical model for DNA. Int. J. Geometr. Methods Mod. Phys. 2017, 14, 1750152. [CrossRef]

39. Petrov, A. G Flexoelectricity of model and living membranes. Biochim. Biophys. Acta (BBA)-Biomembr. 2002, 1561, 1-25. [CrossRef]

40. Adey, W. Ionic Nonequilibrium Phenomena in Tissue Interactions with Electromagnetic Fields; ACS Publications: Washington, DC, USA, 1981.

41. Alqabandi, J.A.; Abdel-Motal, U.M.; Youcef-Toumi, K. Extracting cancer cell line electrochemical parameters at the single cell level using a microfabricated device. Biotechnol. J. 2009, 4, 216-223. [CrossRef]

42. Ambrose, E.; James, A.; Lowick, J. Differences between the electrical charge carried by normal and homologous tumour cells. Nature 1956, 177, 576. [CrossRef]

43. Becker, R. The electrical control of growth processes. Med. Times 1967, 95, 657-669.

44. Hammerick, K.E.; Longaker, M.T.; Prinz, F.B. In vitro effects of direct current electric fields on adipose-derived stromal cells. Biochem. Biophys. Res. Commun. 2010, 397, 12-17. [CrossRef]

45. Popp, F.A. Cancer growth and its inhibition in terms of coherence. Electromagn. Biol. Med. 2009, $28,53-60$. [CrossRef]

46. Becker, R.O. The basic biological data transmission and control system influenced by electrical forces. Ann. N. Y. Acad. Sci. 1974, 238, 236-241. [CrossRef] [PubMed]

47. Haltiwanger, S. Clinical Use of Mineral Transporters and Their Effects on Cell Membrane Capacitance: Second International Congress of BioEnergetic Medicine; Institute of Quantum and Molecular Medicine: Melbourne, FL, USA, 1998.

48. Blackiston, D.; Adams, D.S.; Lemire, J.M.; Lobikin, M.; Levin, M. Transmembrane potential of GlyCl-expressing instructor cells induces a neoplastic-like conversion of melanocytes via a serotonergic pathway. Dis. Models Mech. 2011, 4, 67-85. [CrossRef] [PubMed]

49. Brewer, A.K.; Passwater, R. Physics of the cell membrane. Mechanisms involved in cancer. Am Lab 1976, 10, 37-45.

50. Ling, G. The association-induction hypothesis. A theoretical foundation provided for the possible beneficial effects of a low $\mathrm{Na}$, high $\mathrm{K}$ diet and other similar regimens in the treatment of patients suffering from debilitating illnesses. Agressol. Rev. Int. Phys.-Biol. Pharmacol. Appl. Eff. L'agression 1983, 24, 293.

51. Cheng, N.; Van Hoof, H.; Bockx, E.; Hoogmartens, M.J;; Mulier, J.C.; De Dijcker, F.J.; Sansen, W.M.; De Loecker, W. The effects of electric currents on ATP generation, protein synthesis, and membrane transport of rat skin. Clin. Orthop. Relat. Res. 1982, 171, 264-272. [CrossRef]

52. Dhar, G.; Sen, S.; Chaudhuri, G. Acid gradient across plasma membrane can drive phosphate bond synthesis in cancer cells: Acidic tumor milieu as a potential energy source. PLoS ONE 2015, 10, e0124070. [CrossRef]

53. Hsu, P.P.; Sabatini., D.M. Cancer cell metabolism: Warburg and beyond. Cell 2008, 134, 703-707. [CrossRef]

54. Marin-Hernandez, A.; Gallardo-Perez, J.C.; Ralph, S.J.; Rodriguez-Enriquez, S.; Moreno-Sanchez, R. HIF-1 $\alpha$ modulates energy metabolism in cancer cells by inducing over-expression of specific glycolytic isoforms. Mini Rev. Med. Chem. 2009, 9, 1084-1101. [CrossRef] 
55. Annibaldi, A.; Widmann, C. Glucose metabolism in cancer cells. Curr. Opin. Clin. Nutr. Metab. Care 2010, 13, 466-470. [CrossRef]

56. Vaupel, P.; Mayer, A. Hypoxia in cancer: Significance and impact on clinical outcome. Cancer Metastasis Rev. 2007, 26, 225-239. [CrossRef]

57. Ojugo, A.S.; McSheehy, P.M.; McIntyre, D.J.; McCoy, C.; Stubbs, M.; Leach, M.O.; Judson, I.R.; Griffiths, J.R. Measurement of the extracellular $\mathrm{pH}$ of solid tumours in mice by magnetic resonance spectroscopy: A comparison of exogenous $19 \mathrm{~F}$ and 31P probes. NMR Biomed. Int. J. Devoted Dev. Appl. Magn. Reson. In Vivo 1999, 12, 495-504.

58. Ridgway, P.F.; Ziprin, P.; Peck, D.H.; Darzi, A.W. Hypoxia increases reepithelialization via an $\alpha \mathrm{v} \beta 6$-dependent pathway. Wound Repair Regen. 2005, 13, 158-164. [CrossRef] [PubMed]

59. Chiche, J.; Ilc, K.; Laferrière, J.; Trottier, E.; Dayan, F.; Mazure, N.M.; Brahimi-Horn, M.C.; Pouysségur, J. Hypoxia-inducible carbonic anhydrase IX and XII promote tumor cell growth by counteracting acidosis through the regulation of the intracellular pH. Cancer Res. 2009, 69, 358-368. [CrossRef] [PubMed]

60. Buchheit, C.L.; Weigel, K.J.; Schafer, Z.T. Cancer cell survival during detachment from the ECM: Multiple barriers to tumour progression. Nature Reviews Cancer 2014, 14, 632-641. [CrossRef]

61. Nukpezah, T,; Golemis, E. A. The Extracellular matrix and ciliary signaling. Curr. Opin. Cell Biol. 2012, 24, 652-661. [CrossRef]

62. Zhuo, Y.; Bellis, S. Emerging role of $\alpha 2,6$-sialic acid as a negative regulator of galectin binding and function. J. Biol. Chem. 2011, 286, 5935-5941. [CrossRef]

63. Board, M.; Colquhoun, A.; Newsholme, E.A. High Km glucose-phosphorylating (glucokinase) activities in a range of tumor cell lines and inhibition of rates of tumor growth by the specific enzyme inhibitor mannoheptulose. Cancer Res. 1995, 55, 3278-3285.

64. Blad, B.; Baldetorp, B. Impedance spectra of tumour tissue in comparison with normal tissue; a possible clinical application for electrical impedance tomography. Physiol. Meas. 1996, 17, A105. [CrossRef]

65. Halter, R.J.; Schned, A.; Heaney, J.; Hartov, A.; Schutz, S.; Paulsen, K.D. Electrical impedance spectroscopy of benign and malignant prostatic tissues. J. Urol. 2008, 179, 1580-1586. [CrossRef]

66. Foster, K.; Schepps, J. Dielectric properties of tumor and normal tissues at radio through microwave frequencies. J. Microw. Power 1981, 16, 107-119. [CrossRef]

67. Belmonte, R.; Tejero, M.; Ferrer, M.; Muniesa, J.M.; Duarte, E.; Cunillera, O.; Escalada, F. Efficacy of low-frequency low-intensity electrotherapy in the treatment of breast cancer-related lymphoedema: A cross-over randomized trial. Clin. Rehabil. 2012, 26, 607-618. [CrossRef] [PubMed]

68. Pekkanen, A.M.; DeWitt, M.R.; Rylander, M.N. Nanoparticle enhanced optical imaging and phototherapy of cancer. J. Biomed. Nanotechnol. 2014, 10, 1677-1712. [CrossRef] [PubMed]

69. Olaku, O.; White, J.D. Herbal therapy use by cancer patients: A literature review on case reports. Eur. J. Cancer 2011, 47, 508-514. [CrossRef] [PubMed]

70. Safarzadeh, E.; Shotorbani, S.S.; Baradaran, B. Herbal medicine as inducers of apoptosis in cancer treatment. Adv. Pharm. Bull. 2014, 4, 421. [PubMed]

71. Tong, J.; Liu, R.; Zhao, L.; Kong, W.; Tang, J. Inhibiting human breast cancer cells (mcf-7) with alternating micro-current at intermediate frequency (acif) in vitro and in vivo. In Proceedings of the World Congress on Medical Physics and Biomedical Engineering, Beijing, China, 26-31 May 2012; pp. 1596-1599.

72. Ulgen, Y.; Sezdi, M. Electrical parameters of human blood. In Proceedings of the 20th Annual International Conference of the IEEE Engineering in Medicine and Biology Society. Vol.20 Biomedical Engineering Towards the Year 2000 and Beyond (Cat. No.98CH36286), Hong Kong, China, 1 November 1998; Volume 6, pp. 2983-2986.

73. Barrera, M.; Chung, J.Y.; Greenberg, M.; Fleming, C. Preliminary investigation of a group intervention for siblings of pediatric cancer patients. Child. Health Care 2002, 31, 131-142. [CrossRef]

74. Hinds, P.S.; Drew, D.; Oakes, L.L.; Fouladi, M.; Spunt, S.L.; Church, C.; Furman, W.L. End-of-life care preferences of pediatric patients with cancer. J. Clin. Oncol. 2005, 23, 9146-9154. [CrossRef]

75. Chow, A.Y.; Chin, C.; Dahl, G.; Rosenthal, D.N. Anthracyclines cause endothelial injury in pediatric cancer patients: A pilot study. J. Clin. Oncol. 2006, 24, 925-928. [CrossRef] 
76. Alemi, M.; Meghdari, A.; Ghanbarzadeh, A.; Moghadam, L.J.; Ghanbarzadeh, A. Impact of a social humanoid robot as a therapy assistant in children cancer treatment. In Proceedings of the International Conference on Social Robotics, Sydney, NSW, Australia, 27-29 October 2014; pp. 11-22.

77. Alemi, M.; Ghanbarzadeh, A.; Meghdari, A.; Moghadam, L.J. Clinical application of a humanoid robot in pediatric cancer interventions. Int. J. Soc. Robot. 2016, 8, 743-759. [CrossRef] 